\title{
Impacts on the Earth by asteroids and comets: assessing the hazard
}

\author{
Clark R. Chapman \& David Morrison
}

\begin{abstract}
There is a 1-in-10,000 chance that a large ( 2-km diameter) asteroid or comet will collide with the Earth during the next century, disrupting the ecosphere and killing a large fraction of the world's population. Although impacts of this magnitude are so infrequent as to be beyond our personal experience, the long-term statistical hazard is comparable to that of many other, more familiar natural disasters, raising the question of whether mitigation measures should be considered.
\end{abstract}

THE remnants of the formation of planets by planetesimal accretion' ${ }^{\prime}$ consist of numerous small objects, called asteroids and comets, which occasionally are perturbed into paths that cross the orbits of the Earth and other planets. Spacecraft exploration of the planets has revealed crater-scarred surfaces that testify to a rain of projectiles that continues today; the initial deluge during planetary accretion ended $\sim 3.8 \times 10^{9}$ yr ago with the Late Heavy Bombardment, but a shower of impacts has continued at an approximately steady rate ever since ${ }^{2}$. Despite rapid rates of erosion and tectonism on Earth, over 140 terrestrial impact scars have been identified ${ }^{3}$. Evidence that the Earth still resides in a swarm of asteroids has grown due to recent improvements in telescopic search techniques; dozens of Earthcrossing asteroids are being found each year ${ }^{4}$. As is statistically inevitable, the ever-increasing discovery rate results in ever more frequent news reports about "near misses"5.

The effect of impacts on the Earth's geological history, its ecosphere and the evolution of life has become a major topic of current interdisciplinary interest, since publication of the Alvarez et al. idea $^{6}$ that the Cretaceous/Tertiary $(\mathrm{K} / \mathrm{T})$ mass extinction was caused by the impact of an asteroid or comet $\sim 10 \mathrm{~km}$ across. The Alvarez hypothesis has become widely accepted ${ }^{7}$ since identification of the probable primary impact site in the Yucatan ${ }^{8}$. Impacts have even been proposed as the dominant trigger for other "punctuated equilibrium" changes in the evolution of species". Also, giant impacts in the early history of our planet are now invoked for the impact frustration of the origin of life (the idea that the Late Heavy Bombardment on Earth prevented a long enough period of environmental tranquillity for life to gain a foothold $)^{10,11}$ and the origin of the Moon by a Mars-sized object striking the Earth ${ }^{12}$.

Concerns about a modern-day hazard from comets striking the Earth were voiced as early as 1705 by Edmund Halley in his A Synopsis of the Astronomy of Comets. Soon after the first Earth-crossing asteroids were discovered about 60 years ago ${ }^{13}$, roughly correct estimates of asteroid impact frequencies and consequences were published ${ }^{14,15}$. In $1947 \sim 100$ craters larger than $1 \mathrm{~m}$ across were formed by the Sikhote-Alin (Siberia) fall of iron meteorites, an event that revived studies of the 1908 airburst over the Tunguska River region of Siberia ${ }^{16}$; the conclusion was that the resulting Tunguska devastation of $>1,000 \mathrm{~km}^{2}$ was caused by an atmospheric impact of a comet or asteroid. In 1981, a NASA sponsored "Spacewatch Workshop"17 called attention to the contemporary hazard associated with such cosmic impacts, and first proposed that projectiles as small as $1 \mathrm{~km}$ in diameter might potentially destabilize the global ecosystem, thereby threatening the continuance of human civilization-an event with consequences far exceeding the direct damage from the impact itself.

Here we review and evaluate the contemporary impact hazard associated with cosmic projectiles of various sizes and types, and we compare it to other natural and human-generated hazards. Most projectiles $<50 \mathrm{~m}$ in diameter, with energies $\leqslant 10$ megatons $\left(1 \mathrm{MT}=4.2 \times 10^{15} \mathrm{~J}\right)$, dissipate the energy harmlessly in the upper atmosphere. A larger object could do severe local damage and, if it struck an urban area without warning, cause many deaths; though such impacts occur somewhere on Earth every century or so (very rarely near cities as urban areas constitute a very small fraction of the Earth's area), we show below that they generally pose a much less serious threat than other natural disasters, such as floods and earthquakes.

A greater risk is from objects large enough to disturb the global ecosystem, precipitate general crop failures, and kill unprecedented numbers of people. The threshold size of object for onset of such global catastrophes is poorly known, but we will argue that it is probably in the range $0.5-5 \mathrm{~km}$. Statistically, the risk from such large impacts is similar to risks from other natural and technological disasters. A qualitative difference, however, shared only by nuclear war, is that a global impact catastrophe could lead to the breakdown of civilization.

Impacts are an extreme case of a low-probability/high-consequence hazard. Individual impacts are now unpredictable as few of the threatening objects have been catalogued, although most could be (within two decades) by a proposed survey ${ }^{18}$. Studies of risk perception, which we briefly review, suggest that the public may become anxious about such a catastrophe as knowledge of Earth-approaching objects increases. The impact hazard is becoming an issue of considerable visibility and public debate $^{19}$, especially because controversial technology (for example, the use of nuclear explosives in deep space) might be required to mitigate the hazard. We conclude by posing questions of public policy raised by the newly recognized importance of the impact hazard.

\section{Impact flux estimates}

To analyse the cosmic impact hazard, we must first determine the flux of comets and asteroids striking the Earth. Due to minimal erosion or geological activity since the end of widespread volcanism on the Moon $3 \times 10^{9} \mathrm{yr}$ ago, the Moon's lava plains have recorded the integrated flux of crater-forming cosmic debris in near-Earth space ${ }^{20}$. The average flux at the top of the Earth's atmosphere can be derived from the lunar flux; it compares well, within errors, with direct estimates from the Earth's own recent cratering record ${ }^{3}$ and with a census of existing Earth-crossing asteroids and comets ${ }^{21} 23$.

The Earth-crossing asteroids include rocky and metallic objects derived from main-belt asteroids through collisional fragmentation and chaotic dynamics; others are probably extinct comet nuclei ${ }^{24}$. Most Earth-crossers will eventually be ejected from the Solar System with the aid of Jupiter's gravity; nearly all the rest will strike a terrestrial planet (about one-third of those will strike the Earth ${ }^{24}$ ). Their bulk properties ${ }^{25}$ range from 
metallic (like iron-nickel meteorites) to stony (like chondritic meteorites) to cometary (low-density silicates, organics and volatiles). The total range in bulk density is about a factor of 10 ( $\sim 8 \mathrm{~g} \mathrm{~cm}^{-3}$ for iron, down to $\leqslant 1 \mathrm{~g} \mathrm{~cm}^{-3}$ for cometary ices); the range in strength is presumably even greater.

By the end of 1992, 163 Earth-crossing asteroids had been catalogued ( $\mathrm{E}$. Bowell, personal communication). The largest is 1627 Ivar, $\sim 8 \mathrm{~km}$ in diameter. From analysis of observational sampling statistics, we know that the census is incomplete for objects smaller than Ivar $^{22}$. The estimated degree of completeness for $\sim 1 \mathrm{~km}$ objects is $<5 \%$, and for 100 -m objects it is $<0.1 \%$ (ref. 18). In addition to asteroids, active comets strike our planet. Although the comet flux (estimated from comet discoveries and recoveries ${ }^{26}$ ) is only a few percent of the asteroid flux for objects of the same size, comets hit faster than the $\sim 20 \mathrm{~km} \mathrm{~s}^{-1}$ typical for asteroids (typically $30-40 \mathrm{~km} \mathrm{~s}^{-1}$ for short-period comets, $50-60 \mathrm{~km} \mathrm{~s}^{-1}$ for long-period comets) $)^{23}$. Therefore, active comets have kinetic energies several times greater than for similar sized asteroids, and constitute a significant share $(\sim 25 \%)$ of the impact hazard ${ }^{18,23}$.

For the present hazard discussion, we adopt the average total impact flux on Earth estimated by Shoemaker ${ }^{21}$ and shown in Fig. 1, which gives impact flux as a function of projectile kinetic energy $\left(\frac{1}{2} m v^{2}\right)$; the equivalent diameter is also labelled, assuming a stony-density object striking at $20 \mathrm{~km} \mathrm{~s}^{-1}$. This curve does not include a claimed enhancement in the current flux of small asteroids $(<50 \mathrm{~m})$ based on discoveries by the Spacewatch programme $^{27}$. But their flux may be overestimated because of an unrealistically low assumed albedo (T. Gehrels, personal communication), their encounter velocities are lower than for typical Earth-approachers ${ }^{28}$, and such small objects do not penetrate the Earth's atmosphere (except the small minority composed of iron $)^{29}$. Figure 1 is consistent with Shoemaker's updated analyses ${ }^{22,30}$ and we believe it represents the impact frequencies of objects $>0.5 \mathrm{~km}$ to within a factor of 2 , and of smaller objects capable of doing damage to within a factor of 5 .

Because of stochastic variability in the process of asteroid and comet break-up, there is a chance for significant temporal variations in the impact flux. 'Comet showers' could lead to major short-term increases in the impact hazard, and it has been argued $^{31}$ that even the $\mathrm{K} / \mathrm{T}$ extinction was due to more than one near-simultaneous impact. For purposes of this review, however, it is adequate to treat terrestrial impacts as occurring randomly in space and time.

\section{Nature of the hazard}

The Earth experiences a constant barrage of cosmic debris. Small particles burn up as visible meteors high in the atmosphere, whereas occasionally rocks survive deceleration in the atmosphere and reach the ground as individual meteorites. There is an extremely small hazard associated with such meteorite falls, and no authenticated human fatality (although automobiles, with their larger cross-section, have been struck a few times, most recently by the Peekskill meteorite on 9 October 1992 (ref. 32)). Larger projectiles, however, can do severe damage, up to and including mass extinctions by objects many kilometres in diameter. In this section we discuss the nature of the hazard posed by projectiles as a function of their sizes and physical properties.

Fireballs and bolides. The Earth's atmosphere represents a significant barrier to cosmic projectiles. Even at megaton energies, most meteoroids break up and are consumed before they reach the lower atmosphere. They are called fireballs or, if they explode, bolides. Figure 1 indicates that a bolide with the energy of the Hiroshima nuclear bomb $(\sim 0.015 \mathrm{MT})$ occurs annually, whereas a few events of megaton energy are expected each century. We are generally unaware of these events, for most occur at very high altitudes and their shock waves do not reach the ground, although they have been observed from surveillance satellites $^{33}$.

\begin{tabular}{|c|c|c|c|c|}
\hline & $\begin{array}{c}\text { Energy } \\
(\mathrm{MT})\end{array}$ & $\begin{array}{c}\text { Asteroid } \\
\text { diameter } \\
(\mathrm{km})\end{array}$ & $\begin{array}{c}\text { Comet } \\
\text { diameter } \\
(\mathrm{km})\end{array}$ & $\begin{array}{c}\text { Typical } \\
\text { interval } \\
\text { (yr) }\end{array}$ \\
\hline Lower limit & $1.5 \times 10^{4}$ & 0.6 & 0.4 & $7 \times 10^{4}$ \\
\hline Nominal & $2 \times 10^{5}$ & 1.5 & 1.0 & $5 \times 10^{5}$ \\
\hline Upper limit & $10^{7}$ & 5 & 3 & $6 \times 10^{6}$ \\
\hline
\end{tabular}

Objects give up most of their kinetic energy in the atmosphere and explode if they encounter a column of atmosphere roughly greater than or equal to their mass (corresponding to $\leqslant 20 \mathrm{~m}$ diameter for a $1 \mathrm{~g} \mathrm{~cm}^{-3}$ object). Actually, substantially larger meteoroids are blocked as a result of aerodynamic stresses that cause flattening, fragmentation, spreading of fragments and rapid braking at high altitude ${ }^{34,35}$. The height of fragmentation depends primarily on the meteoroid's physical strength; only the strongest iron meteoroids reach the ground in one piece. For non-iron meteoroids, the minimum energy required to penetrate to the lower atmosphere is $\sim 10 \mathrm{MT}$, or $\sim 50 \mathrm{~m}$ diameter for a stony object hitting at $20 \mathrm{~km} \mathrm{~s}^{-1}$. Analogous calculations for the thicker atmosphere of Venus ${ }^{36}$ were confirmed by the deficiency of smaller craters observed by the Magellan spacecraft.

Locally devastating impacts. If a large meteoroid is able to penetrate to within $\sim 25 \mathrm{~km}$ of the surface (or actually strikes) at velocities of tens of kilometres per second, the resulting explosion can cause severe damage analogous to that from nuclear bomb explosions of similar energies, but without neutron or $\gamma$ radiation, or radioactive fallout. It is well known from civil defence studies that the area of devastation scales approximately as the explosive yield to the $2 / 3$ power, and is somewhat greater for a (low) airburst than for a groundburst explosion ${ }^{37}$.

The 1908 Tunguska airburst provides a calibration, with a shock wave sufficient to fell trees over an area of $\gtrsim 1,000 \mathrm{~km}^{2}$ and a fireball that ignited fires over a smaller area near ground zero. The yield of the Tunguska blast has been estimated at 10 20 MT from microbarograph measurements in Europe and other methods ${ }^{34}$. If we assume that the radius of forest devastation would apply also to destruction of nearly all buildings (chiefly poorly constructed residences), which would thus kill most people, the area of lethal damage is given by $A=100 Y^{2 / 3}$, where $Y$ is the yield in MT and $A$ is in $\mathrm{km}^{2}$. This corresponds to an overpressure of about 4 p.s.i. $\left(=2.8 \times 10^{5} \mathrm{dyn}^{-3}\right)^{35}$.

An example of a locally devastating object would be a stony or metallic projectile $250 \mathrm{~m}$ diameter (1,000 MT energy), which would easily penetrate to the surface; if it struck land, it would produce a crater $5 \mathrm{~km}$ in diameter. (A comet of similar dimensions would fragment before reaching the surface, but its fragments would not thoroughly disperse, and the airburst would have very damaging effects on the ground). Such 1,000-MT events happen every $\sim 10^{4} \mathrm{yr}$; that is, their probability of happening during a person's lifetime approaches $1 \%$. The area of devastation is $\sim 10^{4} \mathrm{~km}^{2}$, or $0.002 \%$ of the Earth's area. Terrible though such an explosion would be, the damage and mortality would remain essentially local (or along coastlines, for ocean impacts), and most of the planet's population would be unaffected.

Globally catastrophic impacts. Rarer impacts of sufficiently great energy would have global consequences in addition to local devastation near the impact site. An obvious if extreme example is the $\mathrm{K} / \mathrm{T}$ impact $65 \times 10^{6} \mathrm{yr}$ ago, which disrupted the global ecosystem and is widely believed to have caused the extinction of more than half the species on Earth $^{6,7}$. The K/T impact of a $10-\mathrm{km}$ object (nearly $10^{8} \mathrm{MT}$ ) excavated a crater (Chicxulub) $180 \mathrm{~km}$ in diameter (we use the original estimates of object size and energy ${ }^{6}$ and of crater size, although recent evidence suggests that the event and resulting crater were $\operatorname{larger}^{38}$ ); it apparently resulted in devastating wildfires ${ }^{39}$ and changes in atmospheric and oceanic chemistry ${ }^{40}$ as well as a dramatic short-term pertur- 
bation in climate ${ }^{41}$ produced by some $10^{16} \mathrm{~kg}$ of submicrometre dust injected into the stratosphere.

The $\mathrm{K} / \mathrm{T}$ impact was probably the largest such terrestrial event in the last $10^{8}$ (or even $10^{9}$ ) yr. Much less massive projectiles can, however, still affect the global climate by injecting dust into the stratosphere ${ }^{41,42}$. Far short of a mass extinction of species, there still could be climate changes sufficient to dramatically reduce crop yields and trigger mass human starvation ${ }^{43}$. Many implications of such short-term climate change have been studied in the context of nuclear winter ${ }^{44,45}$, which is analogous in some ways to a global impact catastrophe.

There is uncertainty about the threshold impact energy for global catastrophe. Quite apart from particular differences of one impact compared with another (comet/asteroid, Southern/ Northern Hemisphere impact, character of 'ground zero', season, incidence angle, and so on), there are large uncertainties in the environmental consequences of impact and, even more, in the effects on human civilization. The combined uncertainty could be expressed as an uncertainty in the number of deaths that would be caused by an impact of specified energy, or it can be expressed equivalently as an uncertainty in the size of object that would kill a specified fraction of the population. For the present discussion, we choose the latter approach and define a globally catastrophic impact as one that would disrupt global agricultural production and lead, directly or indirectly, to the deaths of more than a quarter of the world's population $(>1.5$ billion people).

To appreciate the scale of the global catastrophe we have defined, we must be clear what it is not. We are dealing with the breakdown of organized agriculture but not with the collapse of most natural ecosystems. We are talking about a calamity far larger than the effects of the great world wars but far smaller than the $\mathrm{K} / \mathrm{T}$ impact. We are considering a catastrophe that would destabilize modern civilization, but not an apocalypse that would threaten the survival of the human species.

Threshold for a global impact catastrophe. Having defined a global catastrophe as one that leads to the death of $25 \%$ of the world's population, we now consider what size of colliding object

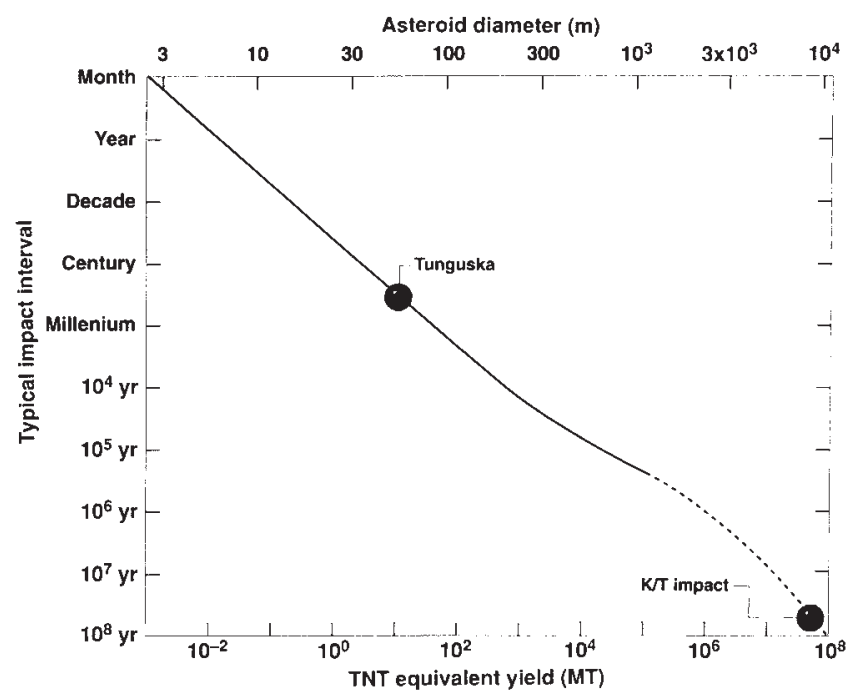

FIG. 1 Typical intervals between impacts equal to or larger than the specified yields. The solid line is Shoemaker's ${ }^{21}$ "best estimate," extended (dashed line) to a minimum estimate of the $\mathrm{K} / \mathrm{T}$ impact energy ${ }^{6}$. Impact frequencies could be uncertain by a factor of 10 near $0.01 \mathrm{MT}$ and by a factor of 3 for $>100 \mathrm{MT}^{18}$. The current impact rate is dominated by small-number statistics in the region of the dashed line. Equivalent asteroid diameters are shown, assuming $20 \mathrm{~km} \mathrm{~s}^{-1}$ impact velocity and $3 \mathrm{~g} \mathrm{~cm}^{-3}$ density. (hence frequency of such catastrophes) might precipitate such consequences, and we discuss the large range of uncertainty in that size. The concept of a threshold, at the transition from local to global catastrophe, is useful. At the point where local effects of an explosion are augmented by global climatic effects, every nation and person is placed at risk, independent of location relative to the impact. Above such a threshold, the mortality (and other risks) from an impact is dramatically higher. We do not mean that the threshold is sharp; certainly the collection of different physical, environmental, and sociological responses to an impact will blur the distinction between strictly local and thoroughly global consequences (for example, tsunamis produce more-than-local but less-than-global effects). But the atmosphere's capacity to distribute sun-darkening, sub-micrometre dust from a major impact appears to be the global environmental consequence that sets in for the smallest objects ${ }^{42}$, and thus establishes a conceptual global threshold.

A global 'impact winter' will commence ${ }^{42}$ when sufficient submicrometre dust is injected into the stratosphere to produce optical depth $>2$ worldwide for a few months (until the dust falls out), and depress average land temperatures by several to perhaps $10^{\circ} \mathrm{C}$ or more for a period of months ${ }^{41}$ to as long as a year (due to oceanic thermal lag) ${ }^{42}$, causing intermittent killing frosts in mid-latitudes even in summer. This optical depth corresponds to $10^{16} \mathrm{~g}$ of stratospheric aerosol, or $\sim 100$ times as much as was lofted by any of the major volcanic eruptions of the last two centuries, including Pinatubo in 1991 and Tambora (which caused the 'year without summer') in 1816 (ref. 46). Such an environmental shock would surely curtail agriculture production during one growing season ${ }^{43}$. The repercussions would be severe, as few nations store one year's worth of food. Compounded by other effects ${ }^{7}$ of the impact (direct killing of millions, destruction of the ozone layer, widespread acid rain, and so on), this agricultural disaster might precipitate the collapse of global economic, social and political structures ${ }^{45}$.

Scaling from nuclear weapons tests and the $K / T$ event, Toon and his colleagues ${ }^{42}$ find that an optical depth $\approx 2$ would result from a groundburst with a yield of $10^{5}-10^{6} \mathrm{MT}$, corresponding to a diameter of $1-2 \mathrm{~km}$ for a stony object striking at $20 \mathrm{~km} \mathrm{~s}^{-1}$. We adopt impact by a $1.5-\mathrm{km}$-diameter stony object with a yield of $\sim 2 \times 10^{5} \mathrm{MT}$ as the nominal threshold value for a global catastrophe.

The uncertainty in the threshold energy probably exceeds an order of magnitude above or below this value. As Turco et al. ${ }^{45}$ wrote, in a nuclear winter context, "the total impact . . . on biological communities is more uncertain [than are climatic effects] because little is known about the effects of physical stresses on ecosystems ... Thus, the important issue of synergisms between various ecological stresses ... . will not be resolved, [so] the global biological impacts - and hence the human impacts-of nuclear war will remain as the principal uncertainties." To reflect such uncertainties, as well as uncertainties in climate modelling and in other physical and chemical effects of an impact, we adopt (Table 1) a possible range of thresholds from $1.5 \times 10^{4}$ to $10^{7} \mathrm{MT}$ $(0.6-5 \mathrm{~km}$ diameter). It would take a very unfavourable combination of parameters coupled with an assumption that human society is very fragile, to imagine that an object with a diameter of $\leqslant 0.5 \mathrm{~km}$ could produce a global catastrophe; on the other hand, a $>5 \mathrm{~km}$ object would ${ }^{42}$ create a global firestorm and so much darkness from stratospheric opacity that vision would cease - an environmental holocaust certainly exceeding any definition for the onset of global catastrophe.

\section{Hazard analysis}

The area of mortality associated with airbursts or groundbursts from objects larger than our 50-m (10 MT) threshold for penetration into the lower atmosphere depends on terrain, nature of habitation, altitude of blast, and so on. (Here we ignore iron meteoroids, which account for $<3 \%$ of falls and whose potential for cratering the Earth's surface has been well studied by Shoe- 
TABLE 2 Fatality rates and scale of impact for three different estimates of global threshold

\begin{tabular}{|c|c|c|c|c|c|}
\hline Type of event & $\begin{array}{l}\text { Diameter of } \\
\text { impactor }\end{array}$ & $\begin{array}{l}\text { Energy } \\
\text { (MT) }\end{array}$ & $\begin{array}{c}\text { Typical interval } \\
(y \mathrm{r})\end{array}$ & Deaths & $\begin{array}{l}\text { World deaths } \\
\text { per year }\end{array}$ \\
\hline Tunguska-like events & $50-300 m$ & $9-2,000$ & 250 & $5 \times 10^{3}$ & 20 \\
\hline Large sub-global events & $\begin{array}{l}300-600 \mathrm{~m} \\
300-1.5 \mathrm{~km} \\
300-5 \mathrm{~km}\end{array}$ & $\begin{array}{c}2,000-1.5 \times 10^{4} \\
2,000-2.5 \times 10^{5} \\
2,000-10^{7}\end{array}$ & $\begin{array}{l}35 \times 10^{3} \\
25 \times 10^{3} \\
25 \times 10^{3}\end{array}$ & $\begin{array}{r}3 \times 10^{5} \\
5 \times 10^{5} \\
1.2 \times 10^{6}\end{array}$ & $\begin{array}{r}8 \\
20 \\
45\end{array}$ \\
\hline Rare $\mathrm{K} / \mathrm{T}$ scale events & $>10 \mathrm{~km}$ & $10^{8}$ & $10^{8}$ & $5 \times 10^{9}$ & 50 \\
\hline
\end{tabular}

maker et $a l .{ }^{47}$; their results imply that they pose a minimal hazard compared with that of larger, stony objects.) We have assumed above that the zone of mortality is roughly the area of devastation (4 p.s.i. overpressure). Then, for the average world population density of ten people per $\mathrm{km}^{2}$, the average number of fatalities per impact is $\sim 10^{3} \times Y^{2 / 3}$ (sloping solid line in Fig. 2 , bottom diagram, which gives expected fatalities per event for a range of asteroid sizes striking the Earth). Thus an 'average Tunguska' (occurring every few centuries) would cause $\sim 7,000$ deaths. Of course, most of the world's population is concentrated in a tiny fraction of the surface area, so most Tunguskas would strike uninhabited parts of the globe and kill few people or none at all, just as in 1908 .

A projectile hundreds of metres in diameter falling in an ocean could generate tsunamis, threatening populations near the ocean $\operatorname{rim}^{48}$. Evaluation of mortality associated with such phenomena is in its infancy; clearly it depends on the efficacy of warning and rapid evacuation. We generally neglect tsunamis below; certainly catastrophes along shorelines do not compete with catastrophes that affect the whole globe, despite concentrations of population near some coasts. Inclusion of tsunamis might raise mortality from several-hundred-metre bodies by as much as a factor of 10 (J. Pike, manuscript in preparation); such an enhancement is shown schematically in Fig. 2 over the range where tsunamis might dominate the mortality.

Above the threshold for global catastrophe, the number of fatalities is (by definition) $>1.5$ billion. As meteoroid size approaches that of the $\mathrm{K} / \mathrm{T}$ object, virtually the entire population of the planet is likely to perish in the aftermath of the impact. For example, just above the nominal threshold of $2 \times 10^{5} \mathrm{MT}$, the expected average local casualties from the direct blast are, from the expression above, about 3 million (up to 30 million, if tsunamis were included), while indirect casualties are (by definition of the global threshold) 1.5 billion, or a factor of 500 greater. This difference reflects the different areas affected: $0.1 \%$ of the Earth's surface for the direct blast, but the entire surface for the indirect effects.

The threshold range from Table 1 is shown as a shaded area of uncertainty in Fig. 2, bottom; the boundaries of the shaded area are schematic; we do not know the shape of the transition from regional to global effects, nor the rapidity with which the expected mortality above the global threshold approaches the entire population of the planet.

Is the greatest risk from the smaller, more frequent Tunguskalike impacts that cause local or regional mortality and damage, from larger impacts near the global catastrophic threshold, or from the very rare mass extinction events? The results of integrating the fatalities multiplied by their probability of happening over segments of the impactor size-frequency distribution are shown in Table 2 for the three estimates of global thresholds given in Table 1. A schematic representation of how these fatality rates vary with size is shown in Fig. 2, top diagram.

The smaller, frequent events larger than the $10 \mathrm{MT}$ atmospheric cut-off yield annual fatality rates of about 20 deaths per year for the current world population. In reality, of course, hundreds to tens of thousands of years pass with practically no fatalities, followed by an impact that would kill thousands of people in a localized area (at average world population density) or hundreds of thousands of people if it unluckily struck a large urban area. At the high-yield extreme, the $\mathrm{K} / \mathrm{T}$ impact was vastly more devastating; but even though nearly everyone would be killed by such a calamity, they are so infrequent that the annual fatality rate is only about 50 per year for the world's present population ( 5 billion people killed per 100 million years).

Intermediate scale objects $(>300 \mathrm{~m}$ but smaller than the threshold for global effects) have an annual risk similar to that of smaller events, although tsunamis could augment their importance. Just above the threshold for global catastrophe, however, the fatality rate is much higher, especially if the threshold is near our nominal estimate or smaller. If 1.5 billion people are killed by the $2 \times 10^{5}$ MT events that occur every $5 \times 10^{5} \mathrm{yr}$ or so, then the fatality rate is 3,000 per year. The annual risk per individual is about $1: 1,300,000$. The corresponding lifetime risk of exposure to such cosmic bombardment, for a 65 -yr life span, is about $1: 20,000$; those are the odds that you will die as the result of the impact of a comet or asteroid near the threshold.

\section{Perceptions of the hazard}

The nature of the impact hazard is unique in human experience. Nearly all other hazards we face in life actually happen to someone we know, or at least they are reported in the news. Behaviours affecting personal health and safety, such as cigarette smoking and car driving, are overwhelmingly more important to life expectancy than are catastrophes of any sort that affect many people at once. In contrast, few people - if any at allare known to have died in modern times from the impact of an extraterrestrial object, and the chances are very small that anyone (or everyone) will be killed by impact anytime during the next century. Thus our personal expectation of dying from an impact is extremely small, in spite of a surprisingly high level of statistical risk.

Let us consider the impact hazard compared with other hazards. Before turning to the globally catastrophic impacts, we first discuss the smaller, more frequent impacts below the global threshold. The data in Fig. 2 imply that in the next $100 \mathrm{yr}$ there is about a $1 \%$ chance of an impact $>1,000 \mathrm{MT}$ (for example, 100 Tunguskas at once or $10 \%$ of the world's combined nuclear arsenal), which could have happened if asteriod 1989 FC had struck the Earth rather than passing by at less than twice the distance to the Moon, as it did in 1989 (ref. 49). Such an impact 
could be horribly devastating, and millions of people could be killed in the unlikely event that an urban centre were struck. However, the scale of such an impact is not greatly different from that of much more common disasters. The very worst technological accidents of modern society, like the Bhopal disaster or airline crashes, affect only hundreds or, at most, thousands of people at once. The dominant cause of catastrophic death during recorded history ${ }^{50}$ has been from natural disasters, wars, and-especially - the famines and epidemics that have killed tens of millions of people. Even in the twentieth century, there have been at least 10 separate natural disasters (during 1900-1985) that killed 100,000 to $2,000,000$ people each, including 4 earthquakes, 3 floods, 2 droughts and 1 cyclone ${ }^{51}$. Tunguskaclass impacts $(10 \mathrm{MT})$ in populated areas are at least 100 times less frequent ${ }^{52,53}$ than the floods, cyclones, and earthquakes that are similarly lethal (kill 10,000 or more people). Local and regional scale impacts should not be ignored, but steps to mitigate them should be evaluated by a cost-benefit analysis that is aware of the much larger probability indeed certainty of future non-impact disasters of comparable or greater magnitude.

A globally catastrophic impact, however, exceeds all other disasters in that such an event could kill much of the world's population over the course of a few months or years. Not even the worst natural catastrophes compare with a global impact catastrophe. Tornados, cyclones, earthquakes, tsunamis, volcanic eruptions, firestorms and floods all have limits. The frequencies of the very biggest and rarest natural catastrophes are poorly known, but they must-at some magnitude-drop to zero (which is not true for impacts) because there are absolute upper limits to the amount of strain that can build up in the Earth's crust, to the power of atmospheric storms, and so on.

Furthermore, the globally catastrophic impact is qualitatively different from other more familiar hazards in its synergistic effects upon the entire planet. Even the nations most affected by the world wars of this century, in which tens of millions of people were killed and infrastructure was substantially destroyed, were able to return to productivity and a high living standard within a decade or so. This would not be expected in the aftermath of a globally catastrophic impact, because by definition it undermines all nations, which therefore cannot help each other.

One way to consider the impact hazard is to compare its statistical risk (dominated, of course, by the rare, globally catastrophic impacts, rather than more frequent, smaller impacts) with those of other hazards we face in the modern world. Table 3 gives the chances of death from selected types of accidents and natural disasters for the 'average' American obtained from the risk-assessment literature ${ }^{54-56}$; they typically have uncertainties of $\sim 30 \%$, but some uncommon, controversial, or poorly understood hazards are uncertain by a factor of three. Risks can be much higher for selected individuals (for example, airline pilots, or backpackers in grizzly-bear country). Such risks as car accidents (but not tornados) are roughly similar for developed countries other than the United States; flooding and earthquakes have been far more damaging in some Asian countries than in the United States.

Each typical person (in the United States) stands a similar chance of dying in an asteroid impact as in an aeroplane crash or in a flood. By the straight odds of being killed, the impact threat is as serious as some hazards that most people take very seriously and that governments spend appreciable money to mitigate. Indeed, by the straight odds of death - the chances of a typical US citizen's epitaph reading that they died by Cause $\mathrm{X}$ - the impact threat is much higher than widely publicized threats from certain carcinogens, poisoning by commercial foods and pills that have been deliberately tampered with, wild animals like grizzly bears, fireworks accidents, terrorist bombs and airline hijacking.

How do we relate to such statistics? Let us examine them in a different way. Figure 3 plots some of the hazards in Table 3 as a function of the number of people killed in a single event.
For instance, most murder or accidental electrocution incidents kill one person at a time, whereas most deaths in airliner crashes occur in tragedies that can kill hundreds of people at once. In that sense, air crashes are 'rare/high consequence' events compared with 'frequent/low consequence' events in which a single individual dies at a time. Apparently, the number killed at once is viewed as being more important than total death rate, so airliner crashes receive wide attention in the news media compared with electrocutions, despite even lower risks of death. Impacts are so extreme on this scale, being exceedingly rare but extraordinarily high-consequence events, that many people feel very differently about this hazard than they do about other numerically equivalent hazards

The overwhelmingly most likely number of people to die by a globally catastrophic impact in the foreseeable future is zero. The juxtaposition of the small probability of occurrence balanced against the enormous consequences if it does happen makes the hazard of 'impact winter' very difficult to think about. We have found ${ }^{57}$ that people have two contrary ways of reacting to recent media discussion of the impact hazard; some dismiss it out-of-hand while others are concerned about it.

One way people think about infrequent hazards is to conclude 'it can't happen to me'. Studies of risk perception indicate that people often regard even an involuntary hazard as being of negli-
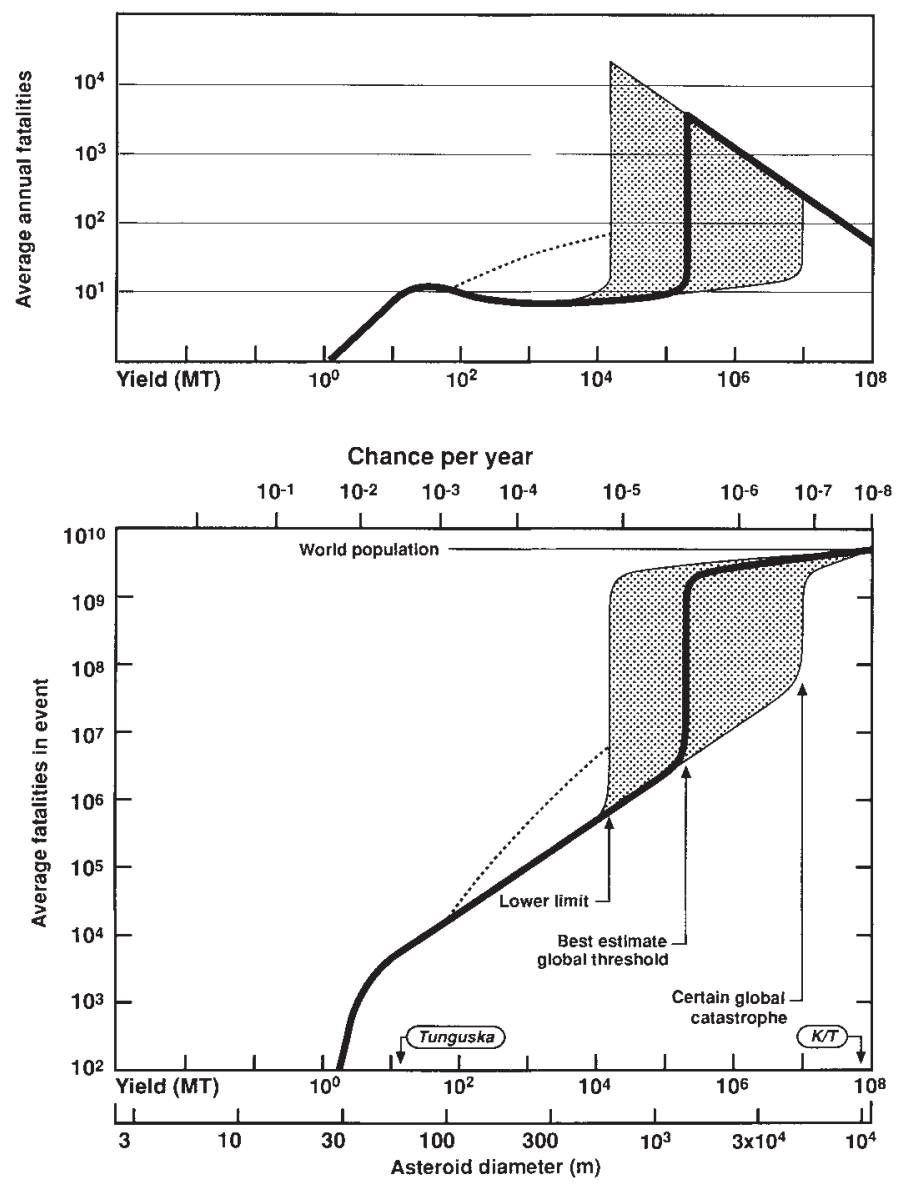

FIG. 2 Bottom, average mortality from impacts of specified yields, for average present population density on the Earth. The dashed line indicates possible enhanced mortality from tsunamis. The shaded region indicates the range of uncertainties in estimates of the threshold for global catastrophe from Table 1. Top, schematic representation of the average fatality rate (deaths per year) from impacts of different sizes. The dashed line and shaded region are as in the bottom part of the figure. Scales for associated asteroid diameters and impact probabilities from Fig. 1 are also shown. 
gible concern if the risk of death per year is one chance in a million, or less ${ }^{54}$. That is why, we suspect, some commentators have reacted to popular discussion of the impact hazard with lack of concern-even cynicism and incredulity that anyone should take the hazard seriously: the impact threat is near that psychological threshold of being dismissed because of its extreme rarity.

On the other hand, studies of risk perception by Slovic ${ }^{58}$ suggest that many people may be inclined to regard a hazard like the impact hazard more seriously than other numerically similar hazards. (Whether people's perceptions should be regarded as a valid basis for government action, or instead dismissed as misperceptions, is a separate issue.) Slovic demonstrates that people's attitudes favouring expenditure of public funds to reduce risks are positively correlated with two factors that describe perceived attributes of hazards: the 'dreadful' nature of a hazard and the degree to which it is 'unknown.' As he defines those factors, the impact threat is both dreadful (globally catastrophic, fatal consequences, high risk to future generations, involuntary) and unknown (not yet observed, newly perceived risk). This may explain why the public and news media have recently expressed such interest in the impact hazard.

Perhaps the distinction between the two antithetical reactions to the impact hazard is that an individual worrying practically about his or her own mortality really has more important things to be concerned about, whereas an individual taking a broader, societal point of view and realizing that a large impact would be devastating, can reasonably wonder whether or not the threat can be mitigated at affordable cost.

\section{Risk reduction and mitigation}

Unlike the species extant before the $\mathrm{K} / \mathrm{T}$ extinction event, human beings now can anticipate and mitigate the impact hazard. Potential impactors (comets or asteroids) can be identified and tracked, and if one is found that poses a near-term threat of impact, we have the technological capability (in principle) to intercept and deflect it. Just such a scenario was studied in 1968 as a senior class project at MIT $^{59}$ and it is the theme of a recent novel ${ }^{60}$. NASA has sponsored several workshops to examine these options, most recently in response to a specific Congressional request (NASA Multiyear Authorization Act, 26 Sept. 1990 ) for options in the two areas of detection and interception.

The NASA Near-Earth Object Detection Workshop proposed a programme ${ }^{18,61}$, called the Spaceguard Survey, that in $20 \mathrm{yr}$ could inventory essentially all potentially threatening asteroids large enough to precipitate a global catastrophe while also providing a lead time of a few months for most incoming comets. The Survey, which would cost $\sim \$ 50$ million for capital construction, and \$10 million per year for operations, could warn us of most large objects plus a fraction of smaller ones down to the atmospheric cut-off. The warning time would typically be several decades for asteroids; for long-period comets, like cousins of Swift-Tuttle, warning time might be only a few months.

The most likely result of the Spaceguard Survey would be to find no objects larger than $1 \mathrm{~km}$ in immediately threatening orbits, and few if any objects of any size that are predicted to strike the Earth within the next century or so. Should such an object be found, however, action could be taken to mitigate the hazard $^{62,63}$. Depending on the nature of the meteoroid and the lead time available, it could be deflected or destroyed ${ }^{64}$; it would be important to avoid fragmenting it into an even more damaging swarm of pieces, which argues for stand-off nuclear explosions rather than surface or buried explosions, or kinetic energy methods. An appropriate impulse, applied by a stand-off explosion of a megaton-range nuclear device a few hundred metres above the surface, could alter the object's orbit so as to remove the immediate impact danger. Warning time of an impact by an asteroid or short-period comet is likely to be long once the Spaceguard Survey is nearly complete, but even if the warning is too short for deflection (as for long-period comets or smaller asteroids), people near the anticipated point of impact could take shelter or be evacuated. The emphasis in a mitigation program would be on protection from the most dangerous objects, those that pose a risk of global catastrophe.

\section{Discussion}

The threat of impacts of asteroids and comets has existed since our planet's formation but it has only recently been recognized as having practical consequences for modern life. The chances that civilization might be disrupted or destroyed by such an impact are very low, but they are not zero. By some measures, they are comparable to other hazards that society takes very seriously.

Society must address the public policy issues raised by the impact hazard and proposals to deal with it. Assuming, as we do, that it is appropriate to tamper with a natural process that may have shaped evolution of life on our planet, there are questions of strategy. For example, in the case of asteroids, a comprehensive sky survey would likely provide decades or more warning, permitting decisions about specific deflection schemes to be deferred until they really are required. But a large comet might be identified on an impact trajectory with a lead time of only a few months; should we prepare in advance to deal-at great expense - with such a contingency, because of its 'unacceptable' consequences, even though it is extremely unlikely?

To date, only a small fraction of the potentially threatening objects have been discovered, but it is well within our capability to inventory most of them. If, as is extremely likely, none of the discovered objects is found to be on a collision course with Earth, then we will know that we are safe, at least from the possibility of an asteroidal impact. Even if it did little to address

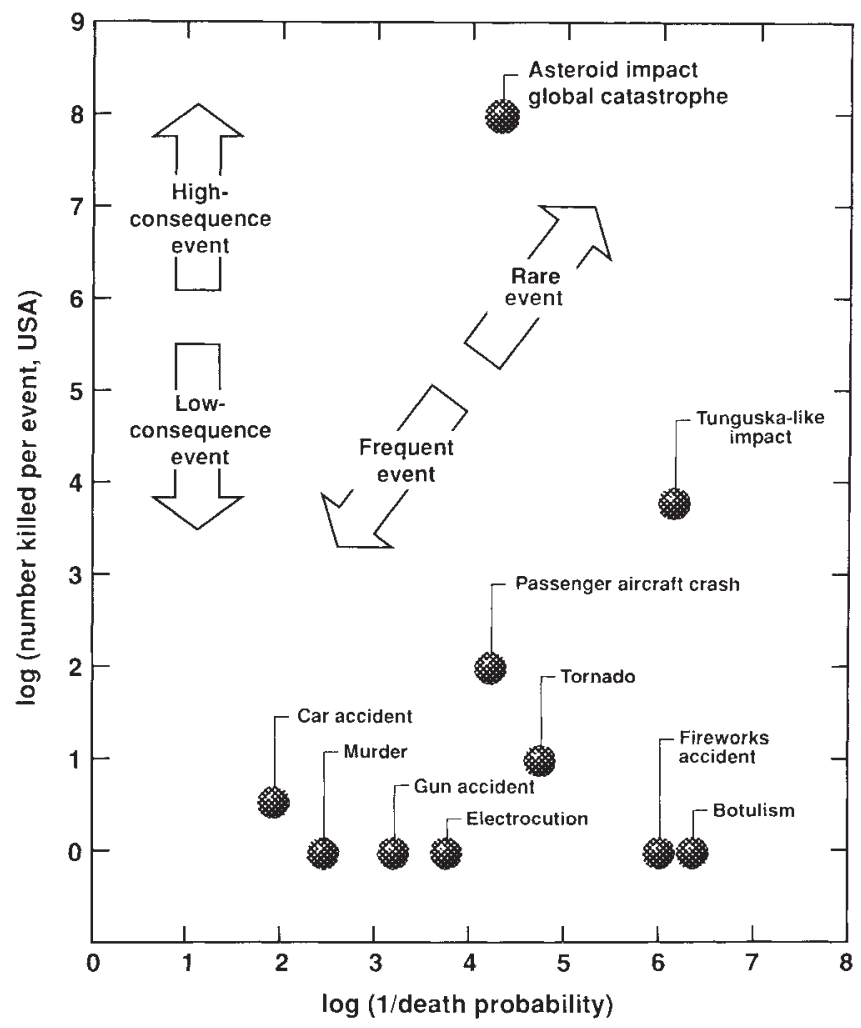

FIG. 3 Impact is an extreme case of a rare but high consequence hazard. For selected hazards (USA), the log of the number of deaths per event is plotted against log of the inverse death probability. Two impact cases are shown (global catastrophe and Tunguska-like events; the global catastrophe case is plotted assuming that the world death rate is applicable to the USA). Trends are shown for very rare and frequent events and for high-consequence and low-consequence events. 
TABLE 3 Chances of dying from selected causes (USA)

$$
\text { Cause of death }
$$

Chances

Motor vehicle accident

Murder

Fire

Firearms accident

Asteroid/comet impact (lower limit)

Electrocution

ASTEROID/COMET IMPACT

Passenger aircraft crash

Flood

Tornado

Venomous bite or sting

Asteroid/comet impact (upper limit)

Fireworks accident

Food poisoning by botulism

Drinking water with EPA limit of TCE*

*EPA, Environmental Protection Agency; TCE, trichloroethylene.

the hazard posed by long-period comets, the asteroid survey alone could reduce the known hazard by at least a factor of three. If, however, we were unlucky and a body were found that would strike the Earth within the next few years or decades, it would probably be possible to divert the body so that it would miss the Earth. In such an eventuality, we expect few would argue against mounting such a mission.

But until a threatening body is actually found, we believe that preparation of a mitigation system would be premature and not cost-effective. It has been argued ${ }^{19}$ that a Spaceguard-like survey costing $\$ 10$ million per year for $30 \mathrm{yr}$ may be worth the cost. Development, testing and actual implementation of a mitigation system (for example, involving launch vehicles and explosive devices) would be much more expensive. Particularly if the system involves controversial and potentially hazardous elements, such as nuclear weapons, society would surely require further expense to lessen the potential for dangerous accidents involving (or misuse of) the mitigation system itself. Therefore, building such a mitigation system would add enormous cost while it would add only modestly to our security, since it would be required only for dangers involving short lead times. For the majority of the most hazardous impactors, we would have time to develop mitigation after an object were discovered.

Although much uncertainty remains about exactly what would happen if a kilometre-scale asteroid were to strike Earth, we know more about what to expect for smaller, more frequent impacts that are likely to occur long before the 'big one'. Should we plan to do something about such events that could cause terrible regional destruction and kill millions? Their hazard is much less than the hazard of other natural catastrophes that can and do kill just as many people much more often; moreover, it would be extremely difficult to discover and inventory all of the countless potential colliding objects down to tens of metres in size. Therefore, maintenance of expensive, active surveillance and inherently risky 'space defences' against small impacts seems to be out of proportion to their threat ${ }^{65}$.

Of course, there is perhaps a much more serious indirect threat from small impacts: misidentification of an asteroid airburst could trigger an inappropriate military response from a nuclear power in times of international tension. High-altitude airbursts with the energy of the Hiroshima bomb occur annually. It is important that such natural phenomena be understood, especially by the military decision-makers of nations with a nuclear capability. This may be the most important immediate issue raised by recognition of the impact hazard.

As public recognition of the impact hazard grows, due to more frequent discoveries and reports of 'near misses' (which is inevitable because of increased sensitivity of telescopic surveys), such questions will increasingly fuel the hazard-mitigation debate. The impact hazard must be considered in parallel with, and balanced against, debates over society's priorities in dealing with other potential ecological disasters and hazards in general. One reason that the impact deserves careful scrutiny is that it has elements that are well-determined compared with other rare, controversial, but less understood hazards. For instance, impact rates are quite well known. Moreover, approaches to mitigation of the most likely impact threats are relatively straightforward, despite being 'high tech'. Thus, by choosing whether or not to do something about this threat from the skies, society may establish a standard against which its responses to other hazards are measured.

Clark R. Chapman is at the Planetary Science Institute, Science Applications International Corporation, $620 \mathrm{~N}$. 6th Avenue, Tucson, Arizona 85705, USA. David Morrison is at the Space Science Division, NASA Ames Research Center, Moffett Field, California 94035, USA.

1. Wetherill, G. W. in Origins and Extinctions (eds Osterbrock, D. E. \& Raven, P. H.) Ch. 2 (Yale Univ. Press, New Haven, 1988).

2. Hartmann, W. K. et al. in Basaltic Volcanism on the Terrestrial Planets 1049-1127 (Basaltic Volcanism Study Project, Lunar and Planetary inst., Pergamon, New York, 1981).

3. Grieve, R. A. F. Meteoritics 26, 175-194 (1991).

4. Helin, E. F. in Asteroids, Comets, Meteors 1991 (eds Harris, A. W. \& Bowell, E.) 235-236 (Lunar \& Planetary Inst., Houston, 1992).

5. Sinnott, R. W. Sky Telesc. 78, (July) 30 (1989)

6. Alvarez, L., Alvarez, W., Asaro, F. \& Michel, H. V. Science 208, 1095-1108 (1980).

7. Sharpton, V. L. \& Ward, P. D. (eds) Global Catastrophes in Earth History (Geol. Soc. Am. Spec. Pap. No. 247, Boulder. 1990).

8. Swisher, C. C. et al. Science 257, 954-958 (1992).

9. Raup, D. M. Extinction: Bad Genes or Bad Luck? (Norton, New York, 1991).

10. Maher, K. A. \& Stevenson, D. J. Nature 331, 612-614 (1988).

11. Sleep, N. H., Zahnle, K. J., Kasting, J. F. \& Morowitz, H. J. Nature 342, 139-142 (1989).

12. Hartmann, W. K., Phillips, R. J. \& Taylor, G. J. (eds) Origin of the Moon (Lunar \& Planetary inst., Houston, 1986).

13. Davidson, M. Mon. Not. R. Astr. Soc. 92, $46(1932)$

14. Watson, F. G. Between the Planets (Harvard Univ. Press, Cambridge, 1941)

15. Baldwin, R. B. The Face of the Moon ix (Univ. Chicago Press, 1949).

16. Krinov, E. E. in The Moon, Meteorites, and Comets (eds Middlehurst, B. M. \& Kuiper, G. P.) Ch. 8 (Univ. Chicago Press, 1963).

17. Chapman, C. R. \& Morrison, D. Cosmic Catastrophes Ch. 19 (Plenum, New York, 1989).

18. Morrison, D. The Spaceguard Survey: Report of the NASA International Near-Earth Object Detection Workshop (NASA/Jet Propulsion Lab., 1992).

19. Editorial The Economist 328, 13-14 (1993).

20. Hartmann, W. K. et al. in Basaltic Volcanism on the Terrestrial Planets Ch. 8 (Pergamon, New York, 1981).

21. Shoemaker, E. M. A. Rev. Earth planet. Sci. 11, 461-494 (1983).

22. Shoemaker, E. M., Wolfe, R. F. \& Shoemaker, C. S. in Global Catastrophes in Earth History (eds Sharpton, V. L. \& Ward, P. D.) 155-170 (Geol. Soc. Am. Spec. Pap. No. 247, Boulder, 1990).

23. Weissman, P. R. in Global Catastrophes in Earth History (eds Sharpton, V. L. \& Ward, P. D.) $171-180$ (Geol. Soc. Am. Spec. Pap. No. 247, Boulder, 1990)

24. Wetherill, G. W. Icarus 76, 1-18 (1988); Meteoritics 24, 15-22 (1989).

25. McFadden, L., Tholen, D. J. \& Veeder, G. J. in Asteroids \# (eds Binzel, R. P., Gehrels, T. \& Matthews, M. S.) 442-467 (Univ. Arizona Press, Tucson, 1989).

26. Everhart, E. Astr. J. 72, 1002-1011 (1967)

27. Rabinowitz, D. L. Astrophys. J. 407, 412-427 (1993)

28. Rabinowitz, D. L. et al Nature $\mathbf{3 6 3}, 704-706$ (1993)

29. Chyba, C. F. Nature 363, 701-703 (1993).

29. Chyba, C. F. Nature 363, 701-703 (1993). to Comets and Asteroids (ed. Gehrels, T.) 73 (Univ. Ariz. Press, Tucson, 1993).

31. Shoemaker, E. M. \& Izett, G. A. Lunar planet. Science (abstr.) 23, 1293 (1992)

32. Di Cicco, D. Sky Telesc. 85, (February) 26 (1993).

33. Jacobs, C. \& Spalding, R. in Conf. Abs. Hazards Due to Comets and Asteroids (ed. Gehrels, T.) 45 (Univ. Ariz. Press, Tucson, 1993).

34. Chyba, C. F., Thomas, P. J. \& Zahnle, K. J. Nature 361, 40-44 (1993).

35. Hills, J. G. \& Goda, M. P. Astr. J. 105, 1114-1144 (1993).

36. Zahnle, K. J. geophys. Res. 97, 10243-10255 (1992).

37. Glassone, S. \& Dolan, P. J. The Effects of Nuclear Weapons 3rd edn (US Govt Print. Off. Washington DC, 1977).

38. Sharpton, V. et al. Science 261, 1564-1567 (1993).

39. Wolbach, W. S., Gilmour, I., Anders, E., Orth, C. J. \& Brooks, R. R. Nature 324, 665-669 (1988).

40. Prinn, R. G. \& Fegley, B. Earth planet. Sci. Lett. 83, 1-15 (1987).

41. Covey, C., Ghan, S. J., Walton, J. J. \& Weissman, P. R. in Global Catastrophes in Earth History (eds Sharpton, V. L. \& Ward, P. D.) 263-270 (Geol. Soc. Am. Spec. Pap. No. 247, Boulder, 1990).

42. Toon, O. B., Zahnle, K., Turco, R. P., Covey, C. in Hazards Due to Comets and Asteroids (ed Gehrels, T.) (Univ. Ariz. Press, Tucson, in the press).

43. Harwell, M. A. \& Hutchinson, T. C. Environmental Consequences of Nuclear War II: Ecological and Agricuitural Effects 2nd edn (Wiley, New York, 1989).

44. Turco, R. P., Toon, O. B., Ackerman, T. P., Pollack, J. B. \& Sagan, C. Science 222, 12831297 (1983).

45. Turco, R. P., Toon, O. B., Ackerman, T. P., Pollack, J. B. \& Sagan, C. A. Rev. Earth planet Sci. 19, 383-422 (1991).

46. Rampino, M. R., Self, S. \& Stothers, R. B. A. Rev. Earth planet. Sci. 16, $73-99$ (1988)

47. Shoemaker, E. M. et al. Meteoritics 25, 409 (1990).

48. Gault, D. E. Sonett, C. P. \& Wedekind, J. A. in 10th Lunar and Planetary Sci. Conf. (abstr.) 422-424 (Lunar \& Planetary Inst., Houston, 1979). 
49. Chapman, C. R., Morrison, D. \& Bowell, E. Meteoritics 24, 258 (1989).

50. Pike, J. Abstr. int. Conf. on Near-Earth Asteroids (San Juan Capistrano Res. inst., San Juan Capistrano, 1991).

51. World Map of Natural Hazards (Münchener Rückversicherungs-Ges. Munich, 1988)

52. Baker, V. R., Benito, G. \& Rudoy, A. N. Science 259, 348-350 (1993).

53. Chinnery, M. A. \& North, R. G. Science 190, 1197-1198 (1975)

54. Starr, C. \& Whipple, C. Science 208, 1114-1119(1980).

55. Wilson, R. \& Crouch, E. A. C. Science 236, 267-270 (1987)

55. Wilson, R. \& Crouch, E. A. C. Science 236, 267-27)
56. Allman, W. F. Science 85, (October) 38-41 (1985).

57. Morrison, D., Chapman, C., Slovic, P. in Hazards Due to Comets and Asteroids (ed Gehrels, T.) (Univ. Ariz. Press, Tucson, in the press).

58. Slovic P. Science 236, 280-285 (1987).

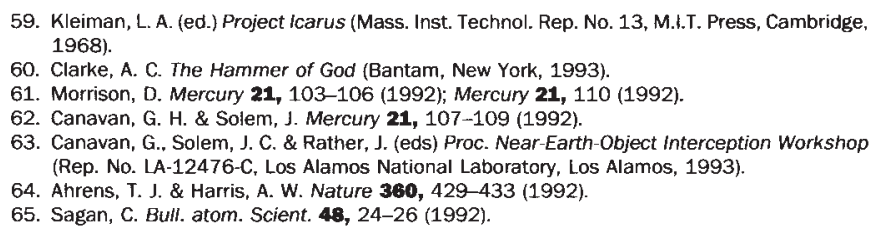

59. Kleiman, L. A. (ed.) Project Icarus (Mass. Inst. Technol. Rep. No. 13, M.l.T. Press, Cambridge 1968).

60. Clarke, A. C. The Hammer of God (Bantam, New York, 1993)

61. Morrison, D. Mercury 21, 103-106 (1992); Mercury 21, 110 (1992).

62. Canavan, G. H. \& Solem, J. Mercury 21, 107-109 (1992).

63. Canavan, G. Solem, J. C. \& Rather, J. (eds) Proc. Near-Earth-Object Interception Workshop

(Rep No IA-12476-C, Los Alamos National Laboratory, Los Alamos, 1993)

64. Ahrens, T. J. \& Harris, A. W. Nature $360,429-433$ (1992)

65. Sagan, C. Bull. atom. Scient. 48, 24-26 (1992).

ACKNOWLEDGEMENTS. We thank K. Zahnle, O. Toon, A. Harris and members of the NASA NEO Detection Workshop for discussions. C.R.C. was supported by NASA Planetary Astronomy.

\title{
ARTICLES
}

\section{A brain serine/threonine protein kinase activated by Cdc42 and Rac1}

\author{
Edward Manser*, Thomas Leung*, Harfizah Salihuddin", Zhuo-shen Zhao* \\ \& Louis Lim ${ }^{* \dagger}$
}

* Glaxo-IMCB Group, Institute of Molecular \& Cell Biology, National University of Singapore, Kent Ridge 0511, Singapore

† Institute of Neurology, 1 Wakefield Street, London WC1N 1PJ, UK

A new brain serine/threonine protein kinase may be a target for the p21 ${ }^{\text {ras }}$-related proteins Cdc42 and Rac1. The kinase sequence is related to that of the yeast protein STE20, implicated in pheromone-response pathways. The kinase complexes specifically with activated (GTPbound) p21, inhibiting p21 GTPase activity and leading to kinase autophosphorylation and activation. Autophosphorylated kinase has a decreased affinity for Cdc42/Rac, freeing the p21 for further stimulatory activities or downregulation by GTPase-activating proteins. This bimolecular interaction provides a model for studying p21 regulation of mammalian phosphorylation signalling pathways.

Although specific functions for several Ras-related small GTP-binding proteins ( $\mathrm{p} 21$ proteins) have been described' ${ }^{4}$, the biochemical targets of these 'molecular switches' remain largely elusive. The exception is Ras itself (most actively studied because of its link to growth control and malignancies ${ }^{5}$ ), whose GTP form can directly modulate adenylyl cyclase in yeast ${ }^{6}$ and mediate uncoupling of potassium channels from the $\mathrm{G}$ protein $\alpha$ subunit, which is effected by the GTPase-activating protein p120 rasGAP in atrial cells', pointing to a role for GAPs in 'downstream' signalling. In addition, genetic and biochemical studies implicate Ras in various growth-factor-stimulated signalling pathways involving both tyrosine and serine/threonine kinases; the target or mediator in these cascades appears to be the serine/ threonine kinase Raf-1 (for reviews, see refs 8 and 9). We have reported a variety of mammalian GAPs for the Ras-related Rho subfamily detected by a novel overlay assay ${ }^{10}$. These p21 proteins, which apparently participate in cytoskeletal actin organization, include: $\mathrm{R}$ ho members $(\mathrm{A}, \mathrm{B}$ and $\mathrm{C})$, implicated in the assembly of focal adhesions and actin stress fibres ${ }^{3}$; two related to the yeast protein $\mathrm{Cdc} 42$ which participates in bud site assembly ${ }^{11}$; Racl involved with membrane ruffling ${ }^{4}$ and possibly with Rac2 in neutrophil oxidase activation ${ }^{12}$; and growth-related p21 RhoG ${ }^{13}$. The GAPs for these proteins that have been identified include rhoGAP, BCR, $n$-chimaerin ${ }^{14}, \beta$-chimaerin ${ }^{15}$ and rasGAP-associated p190 (ref. 16). It is striking that, in addition to the conserved GAP motif, all these proteins have domains that can potentially interact with elements of established intracellular signal transduction pathways ${ }^{17}$.

It appears that the activation of p21s (by exchange of GTP) leads to signals that are both spatially and temporally limited, because the proteins contain functionally essential lipid anchors and possess intrinsic GTPase activity (thereby terminating the signal). The $\mathrm{Rho}$ subfamily differs significantly with respect to rates of GTP exchange and hydrolysis. Rho, like Ras, has a slow intrinsic rate of hydrolysis ${ }^{18}$, but $\mathrm{Rac}$ and $\mathrm{Cdc} 42$ have much shorter half-lives for bound GTP. Conversely, nucleotide exchange is much slower for Rac than $\operatorname{Ras}^{19}$. In vivo these events are probably controlled by interacting proteins, including the $28 \mathrm{~K}\left(M_{\mathrm{r}} 28,000\right)$ GDP-dissociation inhibitor (GDI) which also inhibits intrinsic and GAP-stimulated GTP hydrolysis ${ }^{20}$, and the $d b l$ oncogene product, which stimulates nucleotide exchange for $\mathrm{Cdc} 42$ (ref. 21). Mutations equivalent to Gly $12 \rightarrow$ Val in oncogenic Ras abolish the intrinsic GTPase of Rho proteins, making them unresponsive to GAPs ${ }^{22}$ and resulting in a constitutively activated phenotype for affected cells ${ }^{4}$. This is consistent with a requirement for bound GTP for the effector function.

We have recently characterized a novel hippocampal tyrosine kinase $\mathrm{p} 120^{\mathrm{ACK}}$ (ref. 23), which binds only to the GTP-bound form of $\mathrm{Cdc} 42$; this binding is mediated by a unique region. We have now analysed the p 21 specificity and tissue localization of other proteins binding GTP-p21 proteins and purified one

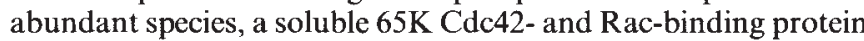
from rat brain. This $\mathrm{p} 65$ protein has protein kinase activity. Its autophosphorylation and kinase activity is stimulated by binding to activated $\mathrm{Rac} / \mathrm{Cdc} 42$, which thereby directly modulates the enzyme. We propose that in vivo activation of these Rho family members leads to the recruitment of different subsets of soluble proteins binding GTP-p21, some of which are protein kinases, that participate in pathways regulated by these $\mathrm{p} 21$ proteins The p65 kinase has sequence identity to the putative protein 